\title{
Prosopografía y redes sociales: notas metodológicas sobre el estudio de la masonería en Costa Rica
}

\author{
Ricardo Martínez Esquivel \\ Profesor de Historia de la Cultura e investigador de la Universidad de Costa Rica. Director de la REHMLAC+. \\ Correo electrónico: ricardo.martinezesquivel@ucr.ac.cr
}

DOI: http://dx.doi.org/10.15517/rehmlac.v7i2.22689

Fecha de recibido: 18 de octubre de 2015 - Fecha de aceptación: 23 de noviembre de 2015

Palabras claves
Historia social, sociabilidad, asociacionismo, modernidad, identidades sociales

Keywords

Social history, sociability, associations, modernity, social identities

\begin{abstract}
Resumen
La prosopografía permite conocer quiénes fueron los masones desde el punto de vista sociológico (características y rasgos sociales), pero también da información sobre la dinámica y la praxis social individual y grupal. Por consiguiente, con la prosopografía es posible construir biografías colectivas de la vida pública y asociativa de los masones. Esto permite acercarse a las relaciones entre la estructura y las dinámicas sociales del grupo de masones, así como a la realidad social y el contexto histórico en que se desenvolvieron. Por lo tanto, en el siguiente trabajo se explica el método prosopográfico y la interpretación de sus resultados según la teoría de redes sociales a partir de la experiencia de investigación sobre la masonería en Costa Rica.
\end{abstract}

\begin{abstract}
Prosopography enables scholars to know not only who the masons were from a sociological point of view (social characteristics and traits), but also provides information on the dynamics and individual and group social praxis. Therefore, with prosopography it is possible to build collective biographies of public and associative life of the masons. This approach explores the relationships between the structure and social dynamics of the group of masons, and to the social reality and the historical context in which they developed. The following work explains the prosopographical method and interpretation of its results according to the theory of social networks, based on the experience of research on Freemasonry in Costa Rica.
\end{abstract}

\section{Introducción}

Los estudios históricos sobre la masonería han sido uno de los temas marginales en la historiografía mundial, quedándose en los paradigmas positivistas del siglo XIX. No obstante, la masonería como objeto de estudio en la Historia ha experimentado un proceso sistemático de modernización en sus formas de análisis e interpretación. En este marco, la academia francesa ha sobresalido en la renovación teórica-metodológica, principalmente con la implementación de la prosopografía, la teoría de las redes sociales y la sociabilidad 
como categoría de análisis ${ }^{1}$. Por consiguiente, pensando en el caso de Centroamérica, en donde no todas las investigaciones producidas desde la Academia que han roto con los tradicionales discursos apologéticos y detractores se pueden situar en los últimos debates historiográficos ${ }^{2}$, la aplicación de estas propuestas teórico-metodológicas han significado un importante aporte en la comprensión de la masonería como objeto de estudio.

En la experiencia del autor de este artículo, la masonería ha funcionado como un laboratorio de ideas, de prácticas culturales, de espacios asociativos y de planteamientos hipotéticos. Por ejemplo, el análisis de 649 masones desde la prosopografía y la teoría de las redes sociales ${ }^{3}$, permitió observar estructuras y prácticas de sociabilidades urbanas y propias de la cultura burguesa en una Costa Rica en pleno proceso de construcción de la modernidad durante el siglo XIX. Además, la masonería al interpretarse desde la sociabilidad ha funcionado como un espejo de diversos grupos sociales, de sus redes, de sus itinerarios personales, políticos, económicos y culturales.

En el marco de una historia social y cultural, el estudiar la masonería ha colaborado en la identificación de los lazos sociales de los masones, percibir sus espacios relacionales y analizar sus relaciones interpersonales. A través del análisis prosopográfico se ha profundizado en el conocimiento de los espacios asociativos de índole político, económico, cultural e intelectual con participación de masones.

Por lo tanto, en las siguientes líneas se realiza un balance del método de investigación social prosopográfico y sus aportes a la Historia de la Masonería en Costa Rica, las fuentes primarias utilizadas y los alcances de la interpretación en términos de redes sociales y sociabilidad de la masonería como objeto historiográfico.

A lo largo del artículo se buscará integrar la bibliografía existente sobre la masonería en Costa Rica ${ }^{4}$.

\footnotetext{
${ }^{1}$ Éric Saunier, Révolution et sociabilité en Normandie au tournant des XVIIIe et XIXe siècles. 6000 francsmaçons de 1740 à 1830 (Rouen : PURH, 1998). Pierre-Yves Beaurepaire, L'espace des francs-maçons. Une sociabilité européenne au XVIIIe siècle (Rennes : Presses universitaires de Rennes, 2003). Céline Sala, Franc-Maçonnerie et Sociabilité. En pays catalan au siècle des Lumières : un particularisme de frontière (Canet: Editions Trabucaire, 2005). Saunier, "La prosopografía: una nueva vía para la Historia de la Masonería", REHMLAC 1, no. 2 (diciembre 2009-abril 2010): 37-42 [citado el 15 de noviembre 2015]: disponible en http://revistas.ucr.ac.cr/index.php/rehmlac/article/view/6616/6305. Charles Porset y Cécile Révauger eds., Le monde maçonnique des Lumières. Europe-Amérique et colonies. Dictionnaire prosopographique (Paris : Honoré Champion, 2013).

2 Ricardo Martínez Esquivel, "Hacia la construcción de una historia social de la masonería en Centroamérica", Revista Estudios 27, no. 1 (2013): 127-151 [citado el 15 de junio de 2015]: disponible en http://revistas.ucr.ac.cr/index.php/estudios/article/view/12703/11951

${ }^{3}$ Martínez Esquivel, "Masones y Masonería en la Costa Rica de los Albores de la Modernidad (1865-1899)" (Tesis de Maestría en Historia, Universidad de Costa Rica, 2012).

${ }^{4}$ En el caso de que no se indique lo contrario, los trabajos citados del autor de este artículo, tratan de análisis prosopográficos y de redes sociales, y la mayoría de ellos, se encuentran en línea y son de libre acceso.
} 


\section{La prosopografía}

La prosopografía es, en pocas palabras, una biografía colectiva de un grupo de actores sociales identificados por una característica en común, la asociación a una logia masónica o teosófica incluso, según sea nuestro interés. A grandes rasgos, consiste en la recopilación sistemática de datos relativos a la vida de los individuos a analizar, tales como sus lugares y fechas de nacimiento y muerte, sus cónyuges, sus descendencias, su vida profesional, así como sus relaciones y actividades sociales. A partir de esta recopilación se busca no sólo llevar a cabo una descripción del grupo como tal, sino ir más allá y realizar un análisis de sus características sociológicas ${ }^{5}$. Así, éste es un método que busca en un punto máximo, acercarse a la realidad social, en donde se analiza el papel actuante del individuo frente a las estructuras, lo cual acerca este método a la microhistoria y a las biografías grupales. De hecho, fue en la década de 1980, por medio de la revista de historia italiana Quaderni Storici, cuando la implementación de la prosopografía y por cierto, el análisis en términos de redes sociales tuvo un fuerte empuje. En Quaderni Storici se planteó la reducción de la escala analítica de la sociedad, privilegiando las acciones de los individuos sobre las estructuras ${ }^{6}$.

El método prosopográfico aplica para cualquier grupo y organización social, pudiendo hacerse diferencias entre grupos religiosos, étnicos, políticos, asociativos, entre tantos y sus relaciones de poder. En el caso de la masonería, los análisis se pueden presentar en forma descriptiva de un caso particular como una región ${ }^{7}$, una $\operatorname{logia}^{8}$ o mediante comparaciones determinadas por otra variable como la participación en la

\footnotetext{
${ }^{5}$ Lawrence Stone, "Prosopografía", en El pasado y el presente, trad. Lorenzo Aldrete (México D.F.: Fondo Económico de Cultura, 1986), 95-120. Eduardo Madrigal Muñoz, "Prosopografía y redes sociales: por un nuevo paradigma historiográfico", en Teoría y métodos de los estudios regionales y locales, eds. Susan Chen Mok, Ana Paulina Malavassi Aguilar y Ronny Viales Hurtado (San José: SIEDIN-Universidad de Costa Rica, 2008), 195-205.

${ }^{6}$ Geovanni Levi, "Sobre Microhistoria”, en Formas de hacer historia, ed. Peter Burke, trad. José Luis Gil Aristu y Francisco Martín Arribas (Madrid: Alianza Universidad, 1993). Madrigal Muñoz “¿Deconstruyendo el Estado? Reflexiones en torno a una renovación teórico-metodológica", Número especial de Diálogos $9^{\circ}$ Congreso de Historia Centroamericano (2008): 3809-3826 [citado el 19 de noviembre de 2015]: disponible en http://historia.fcs.ucr.ac.cr/articulos/2008/especial2008/articulos/12-Teoria/156.pdf

${ }^{7}$ Abilio Jorge Torres, "Composición socio-profesional en la masonería riojana", en Masonería, Política y Sociedad, coord. José Antonio Ferrer Benimeli (Zaragoza: CEHME, 1989), Tomo II, 845-868; Antonio Morales Benítez, "Composición socio-profesional de los masones tarifeños del siglo XIX", Aljaranda: revista de estudios tarifeños 13 (1994 [citado el 15 de octubre de 2015]): disponible en http:/tarifaweb.com/aljaranda/num13/art7.htm; o Sala, «La sociabilité maçonnique française à la croisée des frontières fraternelles et profanes: l'exemple de la ville de Perpignan au XVIIIe siècle », REHMLAC 1, n. 2 (diciembre 2009-abril 2010): 2-16 [citado el 5 de octubre de 2016]: disponible en http://revistas.ucr.ac.cr/index.php/rehmlac/article/view/6614/6303

${ }^{8}$ Torres, "Composición socio-profesional de las Logias 'Zaragoza' en Cuba", en La Masonería Española entre Europa y América, coord. Ferrer Benimeli (Zaragoza: CEHME, 1995), Tomo I, 163-181.
} 
política9. En la prosopografía, por lo general, los resultados se obtienen de procesos deductivos y pueden abarcar la larga duración ${ }^{10}$, coyunturas $^{11}$ o procesos de periodos $\operatorname{cortos}^{12}$. Por lo tanto, se estudia un conjunto de interrelaciones cambiantes al interior de configuraciones en constante adaptación, buscando así acercarse a los comportamientos específicos de individuos y procesos sociales en la construcción de prácticas y discursos culturales $^{13}$. Se llega, entonces, a la posibilidad de observar a niveles micro los procesos de construcción a niveles macro de la historia de la sociedad ${ }^{14}$.

La prosopografía no sólo estudia la estructura de un grupo social específico, sino que ante todo, analiza sus dinámicas sociales, por lo que este método transforma la historia en una herramienta analítica de la sociedad. Es decir, en el caso de los estudios sobre la masonería, permite analizar la incidencia social de la asociación, ya que lleva al investigador a salirse de la logia e identificar los rasgos (características), los vínculos, los desencuentros y la praxis social de los masones. Esto permite cuestionar si la masonería la define su sistema normativo (constituciones, códigos o discursos de las actas) o una dinámica de interacción interna definida por el rito practicado, y no más bien, el accionar individual y grupal de sus miembros.

Por ejemplo, en los resultados de la tesis de maestría en Historia del autor de este artículo, "Masones y Masonería en la Costa Rica de los Albores de la Modernidad (18651899)" (Universidad de Costa Rica, 2012) ${ }^{15}$, se determina la masonería como un producto más de su época y acorde a la realidad del país, compuesta por personas de diferentes intereses, incompresibles por sólo la asociación a una logia masónica e inmersos en la diversidad y la multiplicidad de espacios e ideas promovidos por la sociabilidad moderna. Por consiguiente, la masonería se estableció como una sociabilidad de hombres

\footnotetext{
${ }^{9}$ Cristóbal García García y María Antonia Peña Guerrero, "Masones y políticos: análisis prosopográfico y estudio de su gestión pública en la provincia de Huelva (1876-1936)”, en La Masonería Española y la crisis colonial del 98, coord. Ferrer Benimeli (Barcelona: CEHME, 1999), 775-809. Martínez Esquivel, "Masones y su participación política en Costa Rica (1865-1899)", Número especial de Diálogos $9^{\circ}$ Congreso de Historia Centroamericano (2008): 1815-1848 [citado el 5 de octubre de 2016]: disponible en http://historia.fcs.ucr.ac.cr/articulos/2008/especial2008/articulos/06-politica/76.pdf

${ }^{10}$ Sala, Les Francs-maçons en terres catalanes entre Lumières et Restauration. L'Art Royal de Perpignan à Barcelone (1740-1830) (Paris : Éditions Honoré Champion, 2010).

${ }^{11}$ Yván Pozuelo Andrés, La masonería en Asturias (1931-1939) (Oviedo: Universidad de Oviedo, 2012).

${ }^{12}$ Agnès Renault, "La influencia de la masonería francesa en el Departamento Oriental de Cuba en los años veinte del siglo XIX. Los aportes de la prosopografía”, REHMLAC 1 no. 2 (diciembre 2009-abril 2010): 7489 [citado el 15 de septiembre 2015]: http://revistas.ucr.ac.cr/index.php/rehmlac/article/view/6856/6543

${ }^{13}$ Jacques Revel, « Présentation a Levi, Giovanni », en Le pouvoir au village: Historie d'un exorciste dans le Piémont du XVIIe siècle (Paris : Éditions Gallimard, 1985), XII.

${ }^{14}$ Un ejemplo del alcance de este nivel de análisis es el trabajo de Roger Burt, "Freemasonry and Business Networking during the Victorian Period", Economic History Review LVI, no. 4 (2003): 657-688.

${ }^{15}$ Actualmente en proceso de publicación en la Editorial de la Universidad de Costa Rica.
} 
provenientes de los sectores medios y de las élites de la sociedad, ciudadanos autoconsiderados modernos e ilustrados. Estas personas buscaron organizar "círculos de iguales entre sí"; constituyéndose la logia como un espacio de selección entre una minoría activa y dirigente, sin ejercer necesariamente un monopolio en las funciones tutoras de la sociedad. Así, entonces, la masonería se desenvolvió como una forma de exclusión social y de expansión de sociabilidades organizativas y hegemónicas de círculos restringidos de individuos, satisfaciéndose en ella las necesidades de distinguirse y autorreconocerse como los ciudadanos más notables.

A pesar de esto, la composición social de la logia masónica en la Costa Rica decimonónica se caracterizó por la complejidad, gracias a la gran diversidad de rasgos sociales, de historias de vida y de opciones en los intereses personales de sus miembros.

La prosopografía desarticula la logia e identifica los otros espacios asociativos y las otras redes sociales donde participaron los masones. En Costa Rica, los masones formaron parte de redes económicas, juntas de caridad, mutualidades de artesanos, sociedades educativas, liberales y patrióticas, la prensa, partidos políticos y colegios profesionales, entre otros espacios. La sociabilidad masónica se constituyó para personas con diversos intereses y posiciones, cuyas relaciones se inscribieron en diferentes configuraciones sociales, pero siempre en relación con las transformaciones ocasionadas por la modernidad.

También, la participación en la logia masónica significó un proceso de reconocimiento de rasgos sociales. Hubo logias con mayoría de abogados o comerciantes, católicos o protestantes, costarricenses o extranjeros, hispanoparlantes o angloparlantes. Además, para algunas familias, incluso hasta hoy día, la sociabilidad masónica ha determinado parte de sus identidades como grupo. Por ejemplo, a pesar de no hacerlo desde la prosopografía, Miguel Guzmán-Stein identifica la situación anterior en el caso de los judíos sefarditas en Costa Rica a lo largo del siglo $\mathrm{XX}^{16}$.

Por otra parte, merece su comentario, si la masonería en Costa Rica funcionó como una sociétés de pensée ("sociedad de ideas"), debido al amplio uso de esta categoría de análisis en la historiografía latinoamericana ${ }^{17}$. Este concepto promovido por Augustin $\operatorname{Cochin}^{18}$, Reinhart Koselleck ${ }^{19}$, François Furet ${ }^{20}$ y Jean Pierre Bastian ${ }^{21}$, entre otros ${ }^{22}$,

\footnotetext{
${ }^{16}$ Miguel Guzmán-Stein, "La lapidaria fúnebre-masónica en Costa Rica como fuente de investigación de una comunidad inédita", REHMLAC 1, no. 2 (diciembre 2009-abril 2010): 88-120 [citado el 5 de octubre 2015]: disponible en http://revistas.ucr.ac.cr/index.php/rehmlac/article/view/6619/6308

${ }^{17}$ François-Xavier Guerra, México: del Antiguo Régimen a la Revolución (México D.F.: FCE, 1992), Tomo I, 157-173. David Gueiros Vieira, O protestantismo a maçonaria e a questāo Religosa no Brasil (Brasilia: Editora Universidade de Brasilia, 1980). Héctor Díaz Zermeño, La masonería como sociedad de ideas contrapunteada en el proceso de la independencia de Hispanoamérica y México, 1782-1833 (Madrid, 2009).

${ }^{18}$ Augustin Cochin, Les sociétés de pensée el la démocratie (Paris : Plon, 1921). Cochin, La révolution et la libre pensée (Paris : Plon, 1924).
} 
explica la masonería como una máquina de acción política, conspirativa y revolucionaria, una unidad asociativa que precede a los partidos políticos. Sin embargo, con esta definición se identifican dos problemas. El primero es que politiza la masonería cuando ésta, históricamente, desde sus normativas y estatutos, ha sido definida como apolítica. Y el segundo, es que esta concepción en muchas ocasiones ha colaborado en la consolidación de mitos masónicos en la historiografía. Por ejemplo, se reproducen apologías que explican la masonería como la simiente de las repúblicas y las democracias inspiradas en la Revolución Francesa; así como antimasonerías que definen esta organización como un peligro por sus conspiraciones para el orden sociopolítico ${ }^{23}$. Por consiguiente, se descartó la utilización de la categoría de análisis "sociétés de pensée" no tanto por esta crítica, sino ante todo porque la prosopografía y el análisis de redes sociales aplicados a los masones en Costa Rica, determinaron, que la masonería costarricense y consecuentemente, el proyecto masónico centroamericano, no funcionaron como una "société de pensée".

En el análisis prosopográfico realizado a los masones de Costa Rica del periodo 1865-1899 ${ }^{24}$, se construyeron dos bases de datos sobre el universo básico constituido por los 649 masones identificados. Una vez establecido el universo de análisis con la debida delimitación de las coordenadas cronológicas, geográficas y temáticas, se recolectó de cada individuo en estudio, la mayor cantidad de información de acuerdo con la documentación a la que se tuvo acceso. Lo anterior en un proceso en que se han combinado diferentes

\footnotetext{
${ }^{19}$ Reinhart Koselleck, Critique and crisis. Enlightenment in the Pathogenesis of Modern Society, trad. Berg Publishers Ltd. (Cambridge: MIT Press, 1988), 86-97.

${ }^{20}$ François Furet, Pensar en la Revolución Francesa, trad. Arturo Firpo (Barcelona: Petrel, 1980), $209-227$.

${ }^{21}$ Jean Pierre Bastian, Los disidentes. Sociedades protestantes y revolución en México 1872-1911 (México D.F.: COLMEX, 1989). Bastian, Protestantismo y modernidad latinoamericana. Historia de unas minorías religiosas activas en América Latina (México D. F.: FCE, 1994), 90-105. Bastian, Protestantes, liberales y francmasones. Sociedades de ideas y modernidad en América Latina, siglo XIX (México D. F.: FCE, 1990). Bastian, La modernidad religiosa: Europa latina y América Latina en perspectiva comparada (México D. F.: FCE, 2004).

${ }^{22}$ Ran Halévi, Les loges maçonniques aux origines de la sociabilité démocratique (Paris : Armand Colin, 1984). Keith Baker, Au tribunal de l'opinion. Essais sur l'imaginaire politique au XVIIIe siècle (Paris : Payot, 1992).

${ }^{23}$ Margaret Jacob, Living the Enlightenment: Freemasonry and Politics in Eighteenth-Century Europe. (New York: Oxford University Press, 1991), 12-15. Saunier, «Franc-maçonnerie et Révolution Française: vers une nouvelle orientation historiographique ", Cahiers d'histoire. Revue d'histoire critique 87 (2002 [citado el 16 de setiembre de 2015]): disponible en http://chrhc.revues.org/1672

${ }^{24}$ El periodo 1865-1899 corresponde a un periodo en que la masonería en Costa Rica formó parte de un proyecto masónico centroamericano, 1865 fue el año de la organización de la primera logia masónica en el país y 1899 el de la organización de la Gran Logia de Costa Rica, institución que independizó la masonería costarricense. Para ampliar acerca de las actividades masónicas durante este periodo, puede consultarse: Martínez Esquivel, "Modernity and Freemasonry in 19th Century Central America" (ponencia presentada en Liberalism and Religion: Secularisation and the Public Sphere in the Americas, University of London, 2012 [citado el 10 de octubre de 2015]: disponible en http://sasspace.sas.ac.uk/4146/1/LIA, Modernity and Freemasonry, Martinez, 18.04.12.pdf
} 
fuentes primarias y secundarias. La información recolectada se convirtió en un trabajo de elaboración y ordenamiento de datos, donde las fuentes permitieron construir las bases necesarias para la investigación. Además, el análisis prosopográfico de los masones se realizó comparando los tres periodos de actividades masónicas identificados en Centroamérica: I Periodo (1865-1876) ${ }^{25}$, II Periodo (1880-1885), y III Periodo (1886$1899)^{26}$. Estos periodos se utilizan como matrices analíticas para comparar los grupos de masones en términos socio-ocupacionales, cargos políticos, asociativos, etcétera ${ }^{27}$.

Por lo tanto, se creó "Base de datos Masones en Costa Rica (1865-1899)",28, dividiéndose en once secciones con sus respectivas subdivisiones: (i) datos básicos (nacionalidad, ocupación, religión, entre otros); (ii) vida en la masonería (año de iniciación, logias asociado, cargos, etcétera); (iii) membresía en otras asociaciones (por nombre, número y periodo); (iv) sociedades de beneficencia; (v) cargos políticos (a todos los niveles); (vi) cargos públicos; (vii) propiedades; (viii) estudios realizados (en todos los niveles por años y lugares); (ix) relación con la prensa escrita; (x) docencia; y (xi) otros $\operatorname{datos}^{29}$.

Las fuentes básicas fueron las presentes en el Archivo de la Gran Logia de Costa Rica (AGLCR) y en el Museo de la Gran Logia de Costa Rica (MGLCR) ${ }^{30}$. Estas fuentes

${ }^{25}$ Martínez Esquivel, "Sociedad civil, esfera pública y masonería en Centroamérica (1865-1876)", en Gibraltar, Cádiz, América y la masonería. Constitucionalismo y libertad de prensa, 1812-2012, coord. José Miguel Delgado Idarreta y Antonio Morales Benítez (Gobierno de Gibraltar-Centro de Estudios Históricos de la Masonería Española, Universidad de Zaragoza, 2014), Tomo I, págs. 541-580.

${ }^{26}$ Antes de la presente propuesta, Rafael Obregón Loría y George Bowden, basándose en los cambios de gran logia o en la sede de ésta, propusieron los periodos: 1865-1871, 1871-1887 y 1888-1899; mientras que Miguel Guzmán-Stein, basándose en la propuesta anterior y en los años de vida de las logias masónicas, propuso los periodos: 1865-1874, 1883-1887 y 1888-1899. Ambas periodizaciones sin mayor detalle o explicación. Obregón Loría y Bowden, La masonería en Costa Rica (San José: Trejos Hermanos, 1938), Tomo I, 4. Guzmán-Stein, "Base de datos para la historia de la masonería en Costa Rica en el siglo XIX", en La Masonería en Madrid y en España del siglo XVIII al XXI, coord. Ferrer Benimeli (Zaragoza: CEHME, 2004), Tomo II, 1388-1389. También, en su momento, se optó por utilizar como matriz de análisis, los periodos de organización de logias: 1865-1870, 1873-1875, 1880-1883 y 1886-1903. Martínez Esquivel, "Un estudio comparado del establecimiento de logias masónicas en Costa Rica y Guatemala (1865-1903)", Número especial de Diálogos $9^{\circ}$ Congreso de Historia Centroamericano (2008): 2358-2382 [citado el 10 de octubre de 2015]: disponible en http://historia.fcs.ucr.ac.cr/articulos/2008/especial2008/articulos/07-regional/100.pdf

${ }^{27}$ Véanse: Martínez Esquivel, "Masones y su participación política en Costa Rica (1865-1899)”, 1815-1848. Martínez Esquivel, "Composición socio-ocupacional de los masones del siglo XIX", Diálogos Revista Electrónica de Historia 8, no. 2 (agosto 2007-febrero 2008): 124-147 [citado el 2 de abril 2015]: disponible en http://revistas.ucr.ac.cr/index.php/dialogos/article/view/18344/18536

${ }^{28}$ La investigación sobre la masonería en Costa Rica a partir del siglo XX es todavía una tarea pendiente, a pesar de la publicación de estudios de caso por parte de Miguel Guzmán-Stein y el autor del presente artículo.

${ }_{29}$ Para la creación de bases prosopográficas se puede utilizar desde fichas de cartón hasta programas informáticos como Microsoft Office Excel, Microsoft Office Access, SPSS o File Maker Pro.

${ }^{30}$ Actualmente, Esteban Rodríguez Dobles realiza un trabajo de archivo similiar al realizado sobre la masonería decimonónica en la Sociedad Teosófica de Costa Rica. Rodríguez Dobles, "Redes Esotéricas en Centroamérica y Colombia 1904-1940. El caso de la Sociedad Teosófica" (ponencia presentada en el XIV 
son: (i) ficheros de expedientes, (ii) registros de firmas, (iii) actas de tenidas, (iv) informes de logias, (v) folletos de procedimientos, (vi) anuarios, (vii) álbumes conmemorativos, (viii) prensa masónica y (ix) escritos o reseñas históricas elaborados por masones ${ }^{31}$. El principal documento es el expediente, ya que posee datos como el nombre completo, la fecha y el lugar de nacimiento, los nombres de los padres y la esposa si la tiene, la nacionalidad, la religión, la profesión u ocupación, la residencia, así como los logros masónicos. Lastimosamente, por un lado no existen todos los expedientes de los masones del periodo 1865-1899, y por otro lado, no todos los expedientes que existen están completos. Estos documentos tienen la información necesaria acerca de personas iniciadas o afiliadas a la masonería en el país y el desenvolvimiento de las distintas logias, lo cual es fundamental en la delimitación del universo de análisis. Con las fuentes anteriores se analizó la sociabilidad en la masonería en Costa Rica durante el siglo XIX, su espacio, objeto, funcionalidad, dinámicas, condiciones de acceso y sistema de valores.

Por otra parte, la revisión de documentos en el Archivo Nacional de Costa Rica (ANCR) ha sido fundamental para recabar información básica del grupo en estudio, en especial datos de lugares de nacimiento y muerte, entradas y salidas al país, fuentes oficiales, en especial las censales y leyes, entre otras. Las principales secciones revisadas en el ANCR fueron Beneficencia, Congreso, Expedientes Judiciales, Protocolos y las diversas Secretarías de Gobierno. Asimismo, para identificar los lugares y las fechas de nacimiento de los masones extranjeros, así como sus nacionalidades, parentescos y participación en redes internacionales, fueron esenciales los archivos digitales de la Iglesia de Jesucristo de los Santos de los Últimos Días: Ancestry.com ${ }^{32}$ y Family Search ${ }^{33}$.

En tanto, se recomienda la revisión de fuentes impresas que ofrezcan información individual del grupo en estudio, como diccionarios biográficos, listados de cargos políticos o membresías. Para "Base de datos Masones en Costa Rica (1865-1899)", se utilizaron el

Symposium Internacional de Historia de la Masonería Española. La masonería hispano-lusa y americana. De los absolutismos a las democracias (1815-2015), Universidad de Oviedo, 2015). Rodríguez Dobles, "Las formas de la eternidad y la pugna por el futuro. La Sociedad Teosófica en Costa Rica: imaginarios, creencias y conflictos (1904-1930)" (Tesis de Maestría en Historia, Universidad de Costa Rica, 2016).

${ }^{31}$ Hoy día, el acceso a estas fuentes es más sencillo para el investigador, gracias al convenio de cooperación firmado entre la Gran Logia de Costa Rica y la Universidad de Costa Rica. Niklas Nierhoff, "UCR firmó acuerdo de cooperación con Logia masónica de Costa Rica", Semanario Universidad (10 de noviembre de 2015 [ciatdo el 25 de noviembre de 2015]): disponible en http://semanariouniversidad.ucr.cr/universitarias/ucr-firmo-acuerdo-de-cooperacion-con-logia-masonica-decosta-rica/. Lidiette Guerrero Portilla, "UCR firmó convenio con Logia Masónica de Costa Rica", Oficina de Divulgación e Información de la Universidad de Costa Rica (11 de noviembre de 2015 [ciatdo el 25 de noviembre de 2015]): disponible en http://www.ucr.ac.cr/noticias/2015/11/06/ucr-firmo-convenio-con-logiamasonica-de-costa-rica.html

${ }^{32}$ Sitio Web: http://www.ancestry.com/

${ }^{33}$ Sitio Web: https://familysearch.org/ 
Índice bibliográfico de Costa Rica, de Luis Dobles Segreda ${ }^{34}$; El Poder Legislativo en Costa Rica, de Rafael Obregón Loría ${ }^{35}$; Historia de la Corte Suprema de Justicia de Costa Rica, de Jorge Sáenz Carbonell y Mauricio Masís Pinto ${ }^{36}$; los censos de población y anuarios o censos comerciales ${ }^{37}$; las bases de datos construidas por Iván Molina Jiménez, presentes en el sitio Web de la Escuela de Historia de la Universidad de Costa Rica ${ }^{38}$, son fuentes que permitieron ampliar la información sobre cada individuo. A las anteriores fuentes se agrega la información lapidaria presente en el Cementerio de Extranjeros y en el Cementerio Central, ambos de la ciudad de San José ${ }^{39}$. Además, se resalta la importancia de la historiografía sobre inmigrantes, educación y prensa existente. Todas estas fuentes, primarias y secundarias, permitieron identificar nacionalidades, fechas y lugares de nacimiento y defunción, residencias, ocupaciones, religiones, propiedades, educación y puestos públicos y políticos de muchos de los masones estudiados.

Otras fuentes tomadas en cuenta y claves para el estudio de la masonería de cualquier país católico son las provenientes de la Iglesia Católica. En primera instancia, se tomaron en cuenta las presentes en la sección de Fondos Antiguos del Archivo Histórico Arquidiocesano de la Curia Metropolitana de San José (AHACMSJ):

\footnotetext{
${ }^{34}$ Luis Dobles Segreda, Índice bibliográfico de Costa Rica (San José: Imprenta Lehmann, 1936). De este documento se utilizaron las secciones "Memorias ministeriales", Tomo 5, 511-540; "Catálogo de Abogados", Tomo 8, 303-342; y "Catálogo completo de médicos incorporados y que han ejercido profesión en Costa Rica", Tomo 9, 403-414.

${ }^{35}$ Obregón Loría, El Poder Legislativo en Costa Rica. Segunda Edición Reformada (San José: Impresión Comercial S.A., 1995), 314-388.

${ }^{36}$ Jorge Sáenz Carbonell y Mauricio Masís Pinto, Historia de la Corte Suprema de Justicia de Costa Rica. 180 Aniversario 1826 - 2006 (San José: Editorama, 2006), 111-189.

${ }^{37}$ Oficial, Censo Municipal de San José, 1904 (San José: Imprenta Nacional, 1904), en Víctor Hugo Acuña Ortega y Molina Jiménez, "Base de datos del censo municipal de San José de 1904" (San José: CIHAC, Universidad de Costa Rica, 1992-1997). Oficial, Censo comercial el 31 de diciembre de 1907. Comercios e industrias patentadas (San José: Tipografía Nacional, 1909). Oficial, Censo comercial año 1915 (San José: Imprenta Nacional, 1917). The Latin American Publicity Bureau, Libro Azul de Costa Rica (San José: Imprenta Alsina, 1916). Debido a que muchas de las fuentes anteriores son posteriores al periodo estudiado, en éstas se buscó información que no necesariamente cambia en el tiempo, como años y lugares de nacimiento, nacionalidades y edades, entre otros datos. Esto ya que un individuo masón en 1890 pudo ser cajero de un banco, pero en el censo de 1904 pudo ser un abogado o para los censos comerciales de 1907 o 1915 estuvo dedicado al comercio.

${ }^{38}$ Molina Jiménez, "Base de datos de Compraventas Cafetaleras 1834-1850"; "Base de datos de Electores de Segundo Grado de 1897"; "Base de datos de Electores de Segundo Grado de 1901"; "Base de datos de Maestros de 1904"; "Base de datos de Agricultores de 1911" (San José: Escuela de Historia, Universidad de Costa Rica, Costa Rica [citadas el 25 de octubre de 2015]): disponibles en http://historia.fcs.ucr.ac.cr/bases/ihistoria.html

${ }^{39}$ Un primer trabajo que implementó el uso de fuentes lapidarias fue la investigación de Guzmán-Stein, "La lapidaria fúnebre-masónica en Costa Rica”, 88-120.
} 
- Cartas pastorales contra la masonería publicadas por el Obispo Anselmo Llorente y Lafuente (1851-1871) en el año de 1867.

- Cartas escritas al vicario Domingo Rivas Salvatierra (1871-1877) durante la década de 1870 , en donde diferentes personas se quejaron de la masonería en sus pueblos ${ }^{40}$.

- Correspondencia personal del Obispo Bernardo Augusto Thiel Hoffman (1880-1901) sobre la supuesta influencia masónica en la sociedad costarricense, tanto antes como después de su exilio (1884-1886).

- Abjuraciones a la masonería.

- Artículos publicados sobre la masonería en El Eco Católico de Costa Rica (1883, 1890, 1893 y 1900) y El Adalid Católico (1895-1896) ${ }^{41}$.

Por otra parte, en la Hemeroteca de la Biblioteca Nacional (HBN) se identificó que el Periódico Unión Católica (1890 y 1897) publicó entre 1890 y 1896, numerosos artículos contra la masonería y su supuesta influencia política en Costa Rica. También de la HBN se tomaron en cuenta los distintos periódicos de la época ${ }^{42}$, ya que se identificó la participación de masones en éstos. Los periódicos de la $\mathrm{HBN}$ se pueden consultar en línea ${ }^{43}$.

Además, se estimó importante contemplar el discurso oficial sobre la masonería de la Iglesia Católica dictado desde el Vaticano, por lo que se estudiaron los documentos del Magisterio sobre el tema, todos antimasónicos y de paso escritos por papas. Los textos son de tres tipos:

- Cartas encíclicas: cinco cartas públicas con la función de educar a los feligreses.

- Constituciones apostólicas: dos leyes con direcciones doctrinales, disciplinares y administrativas.

- Bulas: nueve textos breves.

\footnotetext{
${ }^{40}$ Para un estudio de caso de esta situación en la ciudad portuaria de Puntarenas, véase Martínez Esquivel, “Actividades masónicas en la Ciudad de Puntarenas (1870-1876)", Revista Inter Sedes VIII, n. 15 (2010): 93108 [citado el 18 de septiembre de 2015]): disponible en http://revistas.ucr.ac.cr/index.php/intersedes/article/view/870/931

${ }^{41}$ Un análisis de estas fuentes en Martínez Esquivel, "Documentos y discursos católicos antimasónicos en Costa Rica (1865-1899)", REHMLAC 1, no. 1 (mayo-noviembre 2009): 135-154 [citado el 5 de octubre de 2015]): disponible en http://revistas.ucr.ac.cr/index.php/rehmlac/article/view/6860/6547

${ }^{42}$ Explícitamente, los periódicos: La Época (1866), El Costarricense (1873-1876), El Pueblo (1877), El Mensajero (1881-1882), El Tribuno (1882), El Artesano (1883), Gaceta Oficial (1884), Otro Diario (18851886), La Chirimía (1885-1886), Boccaccio (1887), La República (1887-1899), El Gato (1889), El Demócrata (1889), Boletín Electoral (1889), La Prensa Libre (1889-1899), El Heraldo (1890-1892, 1896), Periódico Unión Católica (1890-1896), El Rayo (1896) y La Patria (1896).

${ }^{43}$ Sitio Web: http://www.sinabi.go.cr/biblioteca\%20digital/periodicos/\#.VmpkYyx Oko
} 
Los documentos papales han sido obtenidos de los archivos oficiales de la Iglesia Católica presentes en la $W e b$ en el Archivo Secreto del Vaticano (ASV) ${ }^{44}$, el Cattolicesimo Portale Catolico Apostolico Romano (CPCAR) ${ }^{45}$ y el Totus Tuus Ministries (TTM) ${ }^{46}$.

Las fuentes documentales presentes en el AGLCR, el AHACMSJ, la HBN, el ANCR, así como los textos oficiales del Vaticano y las fuentes digitales citadas, permitieron cruzar fuentes masónicas, eclesiales, oficiales, periodísticas, censales, mortuorias, lapidarias y seculares en general, tanto presentes en archivos costarricenses como extranjeros.

La ventaja primordial de las fuentes expuestas es que permitieron construir la relación cuantitativa-cualitativa que pide el método prosopográfico para ser efectivo, además de que éstas son fuentes útiles para la prosopografía y una interpretación en términos de redes sociales. Por lo anterior, estas fuentes fueron las adecuadas y suficientes para cumplir con los objetivos propuestos. Sin embargo, estas fuentes no ofrecieron la misma información para todos los masones, por lo que, cuando se requirió, los análisis se realizaron por muestras, sean ciudades, periodos cortos, logias, acontecimientos o regiones.

Por último, es necesario recalcar que la prosopografía tiene la limitación de que sin la adecuada dimensión teórica, cae en un mero estudio descriptivo ${ }^{47}$. Dentro de algunos de los resultados de la prosopografía se pueden señalar como limitaciones: (i) la confusión conceptual entre categorías de análisis como agrupación, clase, estrato o red social; (ii) una visión estática del grupo, el cual parece estar caracterizado por una supuesta eternidad e inamovilidad; y (iii) el que no se contemple el carácter dinámico de las sociedades y cómo los diferentes segmentos de éstas van evolucionando. Para evitar tales confusiones es necesario tener un fundamento teórico que brinde una perspectiva analítica y evite caer en un descriptivismo superficial de la población en análisis (el grupo de los masones). Esta perspectiva la provee la teoría de las redes sociales.

\footnotetext{
${ }^{44}$ Sitio Web: http://www.archiviosegretovaticano.va/content/archiviosegretovaticano/it.html

${ }^{45}$ Sitio Web: http://www.cattolicesimo.com/

${ }^{46}$ Sitio Web: http://www.totustuus.com/

${ }^{47}$ De hecho, al inicio de la investigación sobre los masones en Costa Rica, en una primera publicación, se cayó "en un mero estudio descriptivo". Martínez Esquivel, "Composición socio-ocupacional de los masones del siglo XIX", 124-147.
} 


\section{Teoría de las redes sociales}

Uno de los primeros cuestionamientos hechos al obtener los primeros resultados prosopográficos, fue cómo interpretar las distintas dinámicas sociales de los masones, tanto dentro como fuera de la logia masónica. Surge la pregunta de si los masones podían ser categorizados para su análisis como una agrupación social, una clase social, un estrato social o una red social. La respuesta encontrada fue red social, ya que el enfoque de redes sociales permitió observar el dinamismo de las estructuras sociales y la inserción en ellas de las acciones y los roles de los actores individuales, sea en la creación o la transformación de estructuras; es decir, ser testigo de un diálogo permanente entre lo micro (las redes masónicas) y lo macro (la sociedad), visibilizando al sujeto social actuante (los masones).

La red social es el conjunto de relaciones existentes dentro de un grupo determinado de individuos delimitado por un elemento en común, en el caso que interesa definido por quienes participaron en la masonería. En este sentido, al ser las logias masónicas componentes de la sociedad civil y de la esfera pública de la época, a pesar de no ser instituciones estatales se convirtieron en una expresión formalizada de las sociabilidades surgidas durante la modernización de la sociedad; por lo tanto, sus miembros pueden ser entendidos como una red social identificada por el elemento común de pertenecer a esta organización y desenvolverse en su sociabilidad.

La teoría de las redes sociales se planteó por vez primera en el siglo XVIII por Leonard Euler, quien propuso que las estructuras conectadas por líneas y formadas por nodos (puntos), crean gráficos en formas de red, a partir de los cuales es posible sacar distintas conclusiones. Esta presuposición teórica empezó a ser utilizada para estudiar la sociedad, por Paul Erdós, Alfred Rényi y Mark Granovetter, y ha sido ampliamente desarrollada por la Escuela de Chicago de la Psicología de la Gestalt, y la escuela antropológica de Manchester ${ }^{48}$.

La teoría de las redes sociales, siguiendo a Emmanuel Lazega ${ }^{49}$, se puede explicar a partir de cinco supuestos básicos:

1. En la red social existe un conjunto de lazos (relaciones) entre los individuos que la conforman, que posibilitan el intercambio de los recursos (materiales o simbólicos) necesarios para el accionar de éstos en la sociedad; por lo tanto, existen interdependencias recíprocas entre los individuos.

\footnotetext{
${ }^{48}$ Albert-László Barabási, Linked. The New Science of Networks (Cambridge: Perseus Publishing, 2002), 940.

${ }^{49}$ Emmanuel Lazega, Réseaux socisux et structures relationnelles (París: PUF, 1998).
} 
Un caso donde se observa la variable anterior, es la red masónica de parentescos del fundador de la masonería en Costa Rica, el presbítero católico Francisco Calvo ${ }^{50}$ y su primo hermano, el político José María Castro Madriz ${ }^{51}$, la cual, incluyéndoles, se conformó por 92 masones. Entre éstos hubo 28 abogados, de un total de 54 abogados masones del periodo 1865-1899, es decir, más del 50\% de los abogados asociados a una logia masónica, tuvieron, además, lazos familiares con Calvo y Castro Madriz. Asimismo, de los 92 masones de esta red, 90 participaron en las redes políticas costarricenses, ya sea como Presidentes de la República, ministros, diputados, magistrados, alcaldes, presidentes municipales o militando en un partido político. Por lo tanto, se observa en este grupo, una serie de interdependencias múltiples en términos de vínculos o redes.

2. En las redes sociales existe desigualdad entre los individuos participantes, así como los recursos circulantes son escasos, por ende, los participantes en la red social deben desarrollar las estrategias necesarias (debido a la competencia existente entre éstos) para cumplir sus objetivos y metas en la sociedad.

Uno de los acontecimientos más ilustrativos de esta situación en las redes masónicas de Costa Rica, se observa en la arena política. Por ejemplo, en 1868 hubo un golpe de Estado que enfrentó a algunos políticos masones entre sí, ya que unos fueron parte del Gobierno y los otros líderes del grupo de golpistas. Este golpe tuvo como precedente la primera división en una logia costarricense, ya que en la logia Caridad, un grupo de masones, descontentos con el gobierno de Castro Madriz, a la vez venerable maestro de la logia, se retiró para organizar una nueva, para luego, finalmente, algunos de éstos figurar en el grupo de los golpistas. La masonería costarricense se reorganizaría después de un nuevo golpe de Estado (1870), con la participaron de los masones que dieron y recibieron el golpe de Estado de 1868, los cuales, algunos a la vez, participaron juntos en esta nueva insurrección ${ }^{52}$. En estos sucesos se muestra la elaboración de estrategias particulares, con el fin de cumplir objetivos políticos, donde tal vez, el desarrollo de redes de sociabilidad ampliadas, que incluyeron, al menos, lo masónico y lo político, enfrentó, dividió y luego

\footnotetext{
${ }^{50}$ Obregón Loría, Presbítero Doctor Francisco Calvo (Ganganelli). Organizador de la Masonería en Costa Rica (San José: Imprenta Borrase, 1968).

${ }^{51}$ Guzmán-Stein, “Dr. José María Castro Madriz: Masón y liberal, diputado, embajador, ministro, Presidente de la República, Presidente del Congreso, Presidente de la Corte Suprema de Justicia”, en La masonería española en la época de Sagasta (1825-1903), coord. Ferrer Benimeli (Zaragoza: CEHME y la Fundación Práxedes Mateo-Sagasta, 2006), Tomo II, 927-976.

52 Para ampliar acerca del contexto de las relaciones entre el Estado y la masonería de estos años, puede consultarse Guzmán-Stein, "Masonería, Iglesia y Estado: Las relaciones entre el Poder Civil y el Poder Eclesiástico y las formas asociativas en Costa Rica (1865-1875)", REHMLAC 1, no. 1 (mayo-noviembre 2009): 100-134 [citado el 16 de septiembre de 2015]: disponible en http://revistas.ucr.ac.cr/index.php/rehmlac/article/view/6859/6546
} 
unió, a sus participantes, quienes simplemente, compitieron debido a la escases de recursos, en este caso, desde cargos políticos hasta la defensa de un proyecto de sociedad civil.

3. Las relaciones desarrolladas en la red social funcionan como un capital social en el sentido que lo plantea Pierre Bourdieu ${ }^{53}$, por lo que son fundamentales para comprender el accionar de los individuos en la sociedad. A pesar de esto, no todas las relaciones construidas en la red son utilizadas por los individuos, ya que si bien la red es un contrapunto en la utilización de recursos potenciales, también lo es de posibilidades alternativas. Por consiguiente, el hecho de que existan relaciones no implica que se utilicen. Las redes sociales cambian cuando es necesario y nunca son estáticas.

Un caso que refleja lo anterior, se observa cuando uno de los introductores del krausismo en Costa Rica ${ }^{54}$, el canario Juan Fernández Ferraz, tomó la dirección del Instituto Universitario (1884-1887), ya que de los doce profesores titulares, once fueron masones en algún momento de sus vidas. La mayoría de estos educadores coincidieron en el Colegio San Luis Gonzaga y diferentes logias durante la década de 1870. Ante este tipo de situaciones cabe la hipótesis de que estos masones pudieron aprovechar lazos de camarería y amistad, o simplemente relaciones previas (capital social) para satisfacer un interés personal como lo pudo ser el laborar (obtener un empleo) en un instituto secundario o formar parte de un proyecto educativo con determinada filosofía.

4. Los individuos que forman parte de una red social deben ser entendidos como actores sociales y económicos, que están ubicados y determinados, pero que a la vez influyen en el contexto estructural en que se encuentran. Por esta razón es importante estudiarlos en sus distintos rasgos sociales que les caracterizan para comprender su praxis social.

\footnotetext{
${ }^{53}$ Este sociólogo francés plantea que las dimensiones de la vida social se pueden interpretar a partir de campos o espacios de lucha y conflicto sobre un interés específico. En esta lucha se utilizan recursos que Bourdieu conceptualizó como capitales (social, cultural, simbólico, político y económico), los cuales son sinérgicos y necesarios entre sí. Para Bourdieu, el número, la calidad y el uso de las relaciones sociales de cada individuo determinan su capacidad de avanzar en sus intereses desde en el interior de una organización de libre asociación como la masonería, hasta en las estructuras de poder que se producen y reproducen en los campos de lucha de intereses específicos. Pierre Bourdieu, "Avenir de classe et causalité du probable ", Revue Française de Sociologie 15, no. 3 (1974) : 3-42. Bourdieu, "The forms of capital", en Handbook of Theory and Research for the Sociology of Education, ed. John G. Richardson (New York: Greenwood Press 1986), 241-258.

${ }^{54}$ Acerca de las relaciones de la masonería y el krausismo en Costa Rica, revísese Guzmán-Stein, "Masones españoles en Costa Rica: el Krausismo y la Institución Libre de Enseñanza en la formación y desarrollo de la Democracia Liberal Costarricense", en Masonería Española y América, coord. Ferrer Benimeli (Zaragoza: CEHME, 1993), Tomo I, 449-470.
} 
En este sentido, las nuevas formas de sociabilidad brindadas por la modernidad ofrecieron gamas variadas que facilitaron la múltiple militancia en términos asociativos e ideológicos. ¿Qué faceta explica las acciones sociales de un educador como Roberto Brenes Mesén, anarquista, espiritista, masón, rosacruz, socialista y teósofo ${ }^{55}$; o de un literato como José Basileo Acuña, teósofo, masón, espiritista, católico liberal y budista? ${ }^{56}$ En el caso de las religiosidades y las creencias, sin duda alguna, la diversidad de sociabilidades e ideas en un individuo lo determinan las transformaciones estructurales de cada sociedad, es decir, su contexto histórico 57 .

5. Los individuos participantes de la red social son parte de un sistema de valores, normas e instituciones que articulan la forma en que se ejercen el poder, la cooperación y el conflicto en las distintas dinámicas de la sociedad. Las normas son justificaciones de mandatos morales, productos de orden superior (de instituciones que administran las normas), que tienen un código binario de validez (verdadero o falso, justo/correcto o injusto/incorrecto, sí o no, con respecto al otro), con la premisa de que sólo existe una respuesta correcta. En Costa Rica, esta función social la ha tenido la Iglesia Católica, partícipe de la modernidad política ${ }^{58}$ y cultural $^{59}$, determinando en muchas ocasiones los comportamientos y la moral costarricenses ${ }^{60}$. Esto, pensando en el tema masónico, se

\footnotetext{
55 Iván Molina Jiménez, La Ciudad de los monos. Roberto Brenes Mesén, los católicos heredianos y el conflicto cultural de 1907 en Costa Rica (San José: EUCR y EUNA, 2008).

56 José Ricardo Chaves Pacheco, "José Basileo Acuña: teósofo, masón y budista" (ponencia presentada en el IV Simposio Internacional de Historia de la Masonería y los Movimientos Asociativos Latinoamericanos y Caribeños: Prácticas asociativas y Modernidad, siglos XVIII-XXI, Universidad de Costa Rica, 2015).

57 Acerca del contexto histórico durante la vida de estos personajes, véase Martínez Esquivel, "Sociability, Religiosity and New Cosmovisions in Costa Rica at the turn of the Nineteenth to Twentieth Centuries", REHMLAC. Hors série n ${ }^{\circ}$. Special Issue UCLA-Grand Lodge of California (2013): 155-191 [citado el 6 de octubre de 2015]: disponible en http://revistas.ucr.ac.cr/index.php/rehmlac/article/view/22482/22694

58 José Aurelio Sandí Morales, "La Relación Estado e Iglesia católica en Costa Rica 1850-1920. En los procesos de Control del Espacio Geográfico y la Creación de un Modelo de costarricense" (Tesis de Maestría en Historia, Universidad Nacional de Costa Rica, 2009). Esteban Sánchez Solano, "La participación políticopartidista de la Iglesia: El Partido Unión Católica y sus estrategias de movilización política en el marco del conflicto entre la Iglesia Católica y el Estado liberal en Costa Rica (1889-1898)" (Tesis de Maestría en Historia, Universidad de Costa Rica, 2013).

${ }_{59}$ Alfonso González Ortega, Vida cotidiana en la Costa Rica del siglo XIX (San José: EUCR, 1997), 34-42. José Daniel Gil Zúñiga, El culto a la Virgen de los Ángeles (1824-1935). Una aproximación a la mentalidad religiosa en Costa Rica (Alajuela: MHJS, 2004), 9-40.

60 Esteban Rodríguez Dobles, "Reconsiderando el Período Liberal: Mentalidad y Sociabilidad. Propuesta teórica para un estudio de las sociedades de creencias católicas y sus conflictividades ante la modernidad en Costa Rica, 1870-1935", Revista Estudios 22 (2009): 33-48. Sánchez Solano, "La Iglesia católica y el mundo de las ideas: el desafío del liberalismo como espacio social y político en Costa Rica (1850-1900)", en Gibraltar, Cádiz, América y la masonería, Tomo I, 601-623.
} 
observa desde los discursos antiliberales ${ }^{61}$, pasando por la satanización de las logias masónicas y teosóficas o los círculos espiritistas ${ }^{62}$, y hasta las preocupaciones internas o temas principales de debate en los inicios de la Sociedad Teosófica en el país ${ }^{63}$.

Además, la teoría de las redes sociales postula que tanto las leyes e instituciones formales como las prácticas normativas consuetudinarias son un espacio más donde se verifican las estrategias y conflictos de los actores. Por lo tanto, se debe tener en cuenta que los miembros de la masonería no se comportaron necesariamente de acuerdo con el sistema de valores de la logia cuando defienden sus intereses o cuando se ven envueltos en sus conflictos políticos y personales. Así las cosas, hay consciencia de que las estructuras sociales condicionan el acceso a los recursos de los distintos individuos, quienes desarrollan estrategias y maniobras cotidianas, condicionadas por sus variables culturales para así lograr sus intereses.

\section{UCINET: una herramienta para la caracterización de las redes sociales}

Para el análisis de las redes sociales, con fines descriptivos y de obtención de indicadores, se puede utilizar el programa informático $U C I N E T^{64}$, el cual permite obtener la densidad y la cohesión (distancia y alcanzabilidad) de las redes, caracterizar socialmente sus participantes (nodos) e identificar la centralidad, los grados de intermediación y cercanía de los masones, así como quiénes son los participantes (nodos) centrales en cada red. UCINET funciona mejor para graficar grupos pequeños, se puede trabajar con los miembros de una logia en un periodo corto o en acontecimientos como un debate en la prensa, deconstruir un conflicto político o los actores en una reforma educativa. Para el objetivo del presente artículo (mostrar la funcionalidad del programa), se optó por realizar un pequeño ejercicio a la logia Osiris (1945-1946) de la ciudad portuaria de Puntarenas ${ }^{65}$.

\footnotetext{
${ }^{61}$ Sánchez Solano, "La identificación del desarticulador del mundo católico: el liberalismo, la masonería y el protestantismo en la prensa católica en Costa Rica (1880-1900)", REHMLAC 2, no. 2 (diciembre 2010-abril 2011): 34-52 [citado el 6 de octubre de 2015]: disponible en http://revistas.ucr.ac.cr/index.php/rehmlac/article/view/6595/6286

${ }^{62}$ Martínez Esquivel, "Conspiradores políticos y sectas misteriosas: Imaginarios sociales sobre la masonería en Costa Rica (1865-1899)", Revista Estudios 22 (2009): 13-32. Molina Jiménez, La ciencia del momento. Astrología y espiritismo en Costa Rica durante los siglos XIX y XX (Heredia: EUNA, 2011). Rodríguez Dobles, "Los debates periodísticos entre las sociedades de creencias: católicos, espiritistas y teósofos en la Costa Rica del cambio de siglo (1892-1935)", en Gibraltar, Cádiz, América y la masonería, Tomo I, 423-452.

${ }^{63}$ Rodríguez Dobles, "Conflictos en torno a las representaciones sociales del alma y los milagros. La confrontación entre la Iglesia Católica y la Sociedad Teosófica en Costa Rica (1904-1917)”, REHMLAC 2, no. 2 (diciembre 2010-abril 2011): 85-110 [citado el 11 de noviembre de 2015]: disponible en http://revistas.ucr.ac.cr/index.php/rehmlac/article/view/6598/6289

${ }^{64}$ Steven Borgatti, Martin Everett y Lin Freeman, UCINET 6 for Windows User's Guide (Harvard, MA: Analytic Technologies, 2002).

65 Para un análisis completo, puede consultarse Martínez Esquivel, "Sociabilidad moderna, impugnación católica y redes masónicas en la Ciudad de Puntarenas (1870-1951)", en De Puerto a Región: El Pacífico
} 
En el gráfico 1, se observa la red masónica Osiris, construida a partir de las 310 relaciones identificadas: masónicas, ocupacionales, inmigrantes o asociativas de los miembros de la logia. Osiris tuvo 32 miembros, apenas el 5\% de la composición social de la masonería de la Costa Rica de estos años.

\section{Gráfico 1}

Red masónica Osiris de la ciudad de Puntarenas (1945-1951)

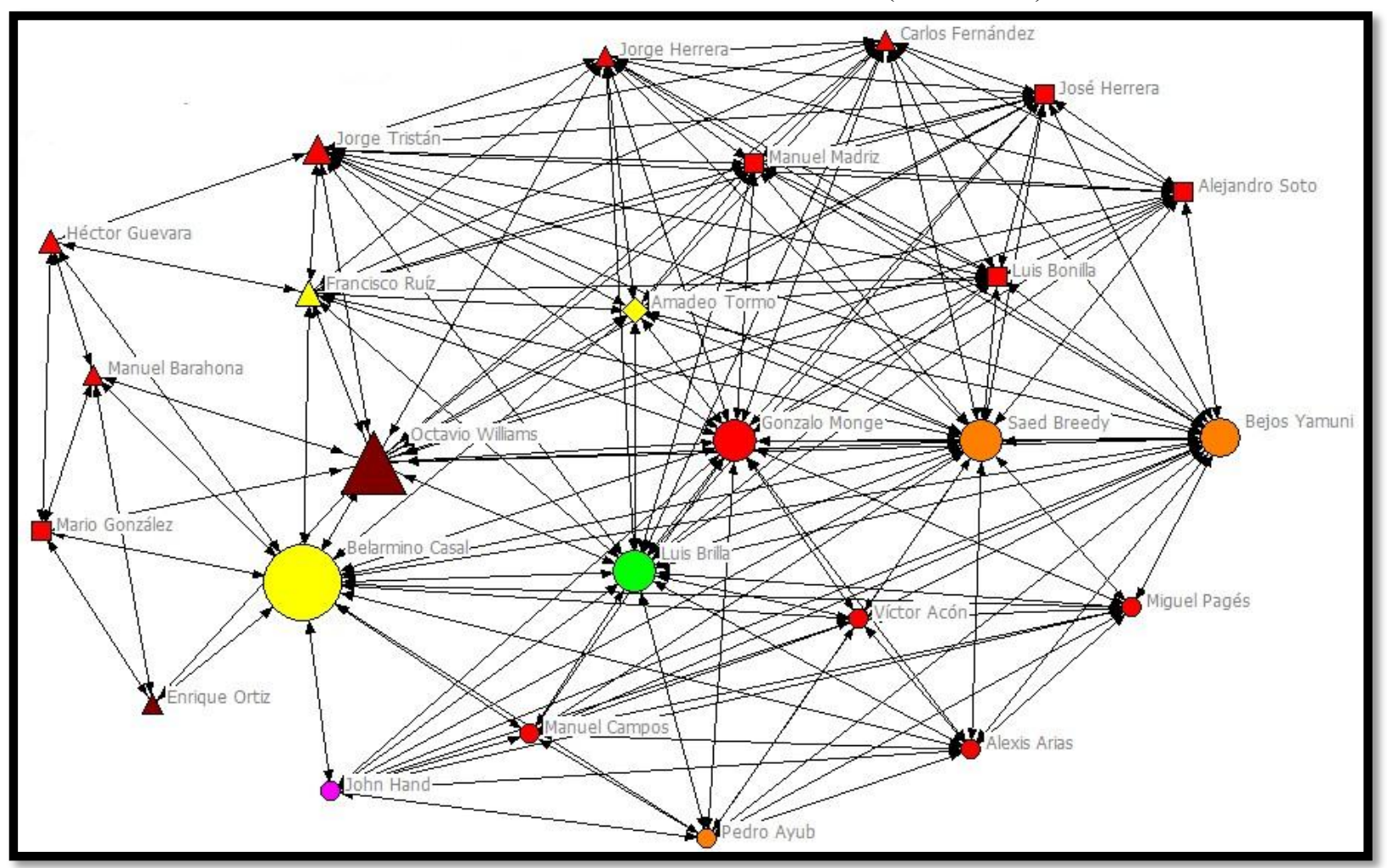

Elaboración propia.

El tamaño de la figura geométrica está determinado por la importancia del subgrupo específico en la red al que pertenece cada masón. Las figuras geométricas representan las profesiones u ocupaciones de cada masón, círculos-comerciantes, triángulos-profesiones liberales, rombos-artesanos y cuadrados-sin identificar. Los colores representan nacionalidades, rojo-costarricenses, amarillo-españoles, naranja-sirio libaneses, cafénicaragüenses, verde-italianos y fucsia-estadounidenses.

Como se observa en el gráfico 1, UCINET, a la hora de construir gráficos, permite caracterizar a los masones. En el caso de la red Osiris, se decidió hacerlo por ocupaciones (figuras geométricas) y nacionalidades (colores). La mayoría de los miembros de esta logia

Central y Sur de Costa Rica 1821-2007, eds. Oriester Abarca Hernández, Jorge Bartels Villanueva y Juan José Marín Hernández (San José: SIEDIN-Universidad de Costa Rica, 2010), 105-142. 
se dedicó al comercio (once personas), hubo tres abogados (Guevara, Ruíz y Tristán) y cuatro médicos (Barahona, González, Ortiz y Williams). Además, estos últimos laboraron en el Hospital de San Rafael de Puntarenas, donde el comerciante español Belarmino Casal formó parte de la Junta de Caridad de dicho hospital y Héctor Guevara Urbina fungió como abogado. ¿Con lo anterior se ha identificado una red de sociabilidad ampliada entre la logia masónica y el hospital? El planteamiento de esta pregunta tiene el fin de mostrar cómo una práctica asociativa (la masonería) y un lugar de trabajo (el hospital), pueden cruzarse y desarrollar una dinámica de sociabilidad. Se necesitaría un análisis más profundo para comprender esta relación logia-hospital y sus roles en el desarrollo de redes, itinerarios o roles de poder en la sociedad puntarenense de la época. Lo que importa aquí consiste en ilustrar la posible utilidad del programa UCINET para una investigación prosopográfica interpretada en términos de redes sociales.

En lo que respecta a las nacionalidades, hubo una mayoría de costarricenses, 22 de 32 , además de tres sirios-libaneses ${ }^{66}$, tres españoles, dos nicaragüenses, un estadounidense y un italiano. No obstante, de los 22 costarricenses, tres fueron descendientes de inmigrantes extranjeros de primera generación: un chino (Víctor Manuel Acón León), un español (Miguel Pagés Quirós) y un alemán (Carlos Manuel Fernández Prestinary). Lo de las nacionalidades es de resaltar, ya que el análisis prosopográfico efectuado a los masones decimonónicos, ha determinado que la masonería no solamente funcionó como un espacio muy importante para la inserción de extranjeros en la sociedad costarricense ${ }^{67}$, sino que además, éstos siempre fueron mayoría en las logias sobre los costarricenses, hasta el punto de convertirse en los líderes de la Orden y en quienes lograron institucionalizar el proyecto asociativo masónico en el país a finales del siglo XIX con la organización de la GLCR.

Por otro lado, la densidad de la red Osiris resultó en un 31,25\%, es decir, se trató de una red dispersa o poco compacta. El análisis de alcanzabilidad indica que cada participante de esta red perfectamente pudo alcanzar una relación con todos los miembros de la logia, ya que para conectar a todos los masones entre sí tan sólo se necesitaron 1,48 relaciones. Y sobre la centralidad de la red, ésta se cifró en un 35,48\%, lo cual quiso decir que no hubo un masón dominante en la red, situación que se observa con mayor claridad en el cuadro 1 ,

\footnotetext{
${ }^{66}$ Acerca de la relación entre masonería e inmigración sirio-libanesa en Costa Rica, véase Martínez Esquivel, "Inmigrantes libaneses en Costa Rica y sus participaciones en la masonería del país (primera mitad del siglo XX)", en 200 años de Iberoamérica (1810-2010), coord. Eduardo Rey Tristán y Patricia Calvo González (Santiago de Compostela: Universidad de Santiago de Compostela, 2010), 268-280 [citado el 11 de noviembre de 2015]: disponible en https://halshs.archivesouvertes.fr/file/index/docid/529294/filename/AT4 MartinezEsquivel.pdf

${ }^{67}$ En particular en los puertos, situación similar también sucedió en el Caribe costarricense: Martínez Esquivel, « La Franc-maçonnerie à Puerto Limon : un espace de réception privilégié du cosmopolitisme dans une ville portuaire », en La Franc-Maçonnerie dans les ports, eds. Cécile Révauger y Saunier (Bordeaux : Presses Universitaires de Bordeaux, 2012), 105-122.
} 
donde se presentan los resultados de los análisis de centralidad y de grados de intermediación.

Cuadro 1

Principales masones de la red masónica Osiris de la ciudad de Puntarenas (1945-1951)

\begin{tabular}{|c|c|c|c|c|c|c|c|c|}
\hline \multirow[t]{2}{*}{ Masón } & \multirow[t]{2}{*}{ Nacionalidad } & \multirow[t]{2}{*}{ Ocupación } & \multirow[t]{2}{*}{$\begin{array}{c}\text { Año de } \\
\text { iniciación }\end{array}$} & \multirow[t]{2}{*}{$\begin{array}{l}\text { Logia de iniciación } \\
\text { (ciudad) }\end{array}$} & \multirow[t]{2}{*}{ Cargo masónico } & \multirow[t]{2}{*}{$\begin{array}{l}\text { Centralidad } \\
\text { en la red }\end{array}$} & \multicolumn{2}{|c|}{$\begin{array}{c}\text { Grado de } \\
\text { intermediación }\end{array}$} \\
\hline & & & & & & & \# & $\%$ \\
\hline Saed Breedy & Siria-Líbano & comerciante & ¿1919? & $\begin{array}{l}\text { Unión Fraternal } \\
\text { (Limón) }\end{array}$ & ninguno & 20 & 15 & 3,4 \\
\hline Luis Brilla & Italia & comerciante & 1945 & $\begin{array}{c}\text { Osiris } \\
\text { (Puntarenas) }\end{array}$ & $\begin{array}{c}\text { venerable maestro de } \\
\text { Osiris }(1945-1946)\end{array}$ & 20 & 15 & 3,4 \\
\hline Gonzalo Monge & Costa Rica & comerciante & 1935 & $\begin{array}{l}\text { Regeneración } \\
\text { (San José) }\end{array}$ & $\begin{array}{c}\text { gran maestro de la } \\
\text { GLCR (1949) }\end{array}$ & 20 & 15 & 3,4 \\
\hline Bejos Yamuni & Siria-Líbano & comerciante & 1905 & $\begin{array}{l}\text { Regeneración } \\
\text { (San José) }\end{array}$ & $\begin{array}{l}\text { gran maestro de la } \\
G L C R(1950)\end{array}$ & 19 & 14 & 3 \\
\hline Belarmino Casal & España & comerciante & 1945 & $\begin{array}{c}\text { Osiris } \\
\text { (Puntarenas) }\end{array}$ & $\begin{array}{c}\text { venerable maestro de } \\
\text { Osiris (1949) }\end{array}$ & 17 & 39 & 8,4 \\
\hline Octavio Williams & Nicaragua & médico & ¿1921? & $\begin{array}{c}\text { Hermes } \\
\text { (San José) }\end{array}$ & $\begin{array}{c}\text { venerable maestro de } \\
\text { Osiris (1947) }\end{array}$ & 17 & 30 & 6,4 \\
\hline
\end{tabular}

En el cuadro 1, se observan los principales masones de la red Osiris, cinco extranjeros y sólo un costarricense, cinco comerciantes y un abogado, datos en línea con los resultados de los análisis prosopográficos realizados a los masones, donde desde la década de 1890 se ha identificado asociándose a las logias masónicas, una mayoría extranjeros y comerciantes $^{68}$. Por último, el cuadro 1 muestra cómo en esta red no hubo un masón dominador, ya que tres de ellos tuvieron 20 relaciones (Breedy, Brilla y Monge) y uno 19 (Yamuni), mientras que los dos con menor número de relaciones (17), Casal y Williams, presentaron mayores grados de intermediación, 8,4\% y 6,4\% respectivamente, es decir, unieron más relaciones, 39 y 30 en el mismo orden. Todo lo anterior, indicadores que colaboran en un análisis prosopográfico más allá de la descripción y aportan datos para contrarrestar en un ejercicio teórico-hipotético desde la teoría de las redes sociales.

En síntesis, el análisis de las redes sociales permite identificar rasgos, imaginarios, discursos y acciones sociales, en consecuencia, es factible interpretar la funcionalidad y la construcción de distintas identidades sociales en los masones. En la red son desenvueltas prácticas socioculturales que configuran formas de reconocerse, intercambiar ideas, desarrollar vínculos de amistad, simpatía y camaradería, lazos tan duraderos como efímeros, satisfacer necesidades, rituales de distinción y modos de comunicación. Sin embargo, la militancia masónica no agota la identidad social del masón, ya que los masones

\footnotetext{
${ }^{68}$ Martínez Esquivel, "Composición socio-ocupacional de los masones del siglo XIX”, 124-147. Martínez Esquivel, "La masonería y el establecimiento de la Sociedad Teosófica en Costa Rica (1904-1910)", en La Masonería Española: Represión y Exilios, coord. Ferrer Benimeli (Zaragoza: CEHME, Gobierno de Aragón, Departamento de Educación, Cultura y Deporte, 2011), Tomo I, 369-392.
} 
participaron de otros espacios con sistemas de valores propios, de los cuales la masonería fue tan sólo uno más, en algunos casos el preponderante, pero en otros no.

\section{Epílogo}

La transformación de los estudios sobre la masonería en Latinoamérica como objeto de las investigaciones científicas continúa siendo un proceso en pleno desarrollo. Se podría datar el inicio del siglo XXI como el comienzo de dicha renovación. En estos 15 años los avances han sido significativos, pero en palabras del editor de la $R E H M L A C+$, Yván Pozuelo Andrés, "los retos futuros son los mismos que los presentes y pasados"69. Es decir, los nuevos autores y la teorización de la masonería como objeto de estudio, no necesariamente representan un ruptura con los clásicos paradigmas de detractores o apologistas de la masonería, tan comúnmente reproducidos en la historiografía latinoamericana contemporánea. No basta con las nuevas fuentes, su cruce con otras o la relectura de las anteriores, mientras que la masonería no se deje de mirar como un tema exótico y necesitado de lecturas especiales, sin integrarse en las posibles y normales variables de la Historia Social, se podría caer en el mismo historicismo de antaño pero disfrazado del discurso de la novedad, la teoría y la crítica a lo anteriormente realizado.

La aportación de la prosopografía y la teoría de las redes sociales ha estado en introducir firmemente al lector al mundo de los masones decimonónicos en Costa Rica, más allá de la logia, mostrando sus perfiles, itinerarios, praxis, redes y proyectos sociales. En resumen, cubriendo un vacío en el muy rico tejido masónico latinoamericano del siglo XIX, avanza y profundiza en la metodología y la investigación de una asociación que aún despierta el interés y la desconfianza, la curiosidad y la cautela, pero por contraste continúa siendo una parte importante de nuestra historia. Por el conocimiento que se produce, este tipo de análisis construye a la masonería como una ventana distinta a la Historia de Costa Rica, a sus transformaciones, y por su propuesta historiográfica, en un referente a tener en cuenta en la actual renovación latinoamericana de la masonería como objeto de estudio.

\footnotetext{
${ }^{69}$ Pozuelo Andrés, "La historiografía masónica latinoamericanista actual. Presente y futuro", en 200 años de Iberoamérica (1810-2010), eds. Eduardo Rey Tristán y Patricia Calvo González (Santiago de Compostela: Universidad de Santiago de Compostela, 2010), 288 [citado el 5 de octubre de 2015]: disponible en https://halshs.archives-ouvertes.fr/file/index/docid/529298/filename/AT4 Pozuelo.pdf
} 


\section{Bibliografía}

Baker, Keith. Au tribunal de l'opinion. Essais sur l'imaginaire politique au XVIIIe siècle. Paris : Payot, 1992.

Bastian, Jean Pierre. Los disidentes. Sociedades protestantes y revolución en México 18721911. México D.F.: COLMEX, 1989.

Bastian, Jean Pierre. Protestantismo y modernidad latinoamericana. Historia de unas minorías religiosas activas en América Latina. México D. F.: FCE, 1994.

Bastian, Jean Pierre. Protestantes, liberales y francmasones. Sociedades de ideas y modernidad en América Latina, siglo XIX. México D. F.: FCE, 1990.

Bastian, Jean Pierre. La modernidad religiosa: Europa latina y América Latina en perspectiva comparada. México D. F.: FCE, 2004.

Beaurepaire, Pierre-Yves. L'espace des francs-maçons. Une sociabilité européenne au XVIIIe siècle. Rennes : Presses universitaires de Rennes, 2003.

Borgatti, Steven, Martin Everett y Lin Freeman. UCINET 6 for Windows User's Guide. Harvard, MA: Analytic Technologies, 2002.

Bourdieu, Pierre. "Avenir de classe et causalité du probable». Revue Française de Sociologie 15, no. 3 (1974) : 3-42.

Bourdieu, Pierre. "The forms of capital". En Handbook of Theory and Research for the Sociology of Education. Editado por John G. Richardson. New York: Greenwood Press 1986.

Burt, Roger. "Freemasonry and Business Networking during the Victorian Period". Economic History Review LVI, no. 4 (2003): 657-688.

Chaves Pacheco, José Ricardo. “José Basileo Acuña: teósofo, masón y budista”. Ponencia presentada en el IV Simposio Internacional de Historia de la Masonería y los Movimientos Asociativos Latinoamericanos y Caribeños: Prácticas asociativas y Modernidad, siglos XVIII-XXI, Universidad de Costa Rica, 2015.

Cochin, Augustin. Les sociétés de pensée el la démocratie. Paris: Plon, 1921.

Cochin, Augustin. La révolution et la libre pensée. Paris: Plon, 1924.

Díaz Zermeño, Héctor. La masonería como sociedad de ideas contrapunteada en el proceso de la independencia de Hispanoamérica y México, 1782-1833. Madrid, 2009.

Ferrer Benimeli, José Antonio. "La Historia ante la masonería. Reflexiones metodológicas". El Basilisco 9 (enero-abril 1980): 31-40.

Furet, François. Pensar en la Revolución Francesa. Traducido por Arturo Firpo. Barcelona: Petrel, 1980. 
García García, Cristóbal y María Antonia Peña Guerrero. "Masones y políticos: análisis prosopográfico y estudio de su gestión pública en la provincia de Huelva (18761936)”. En La Masonería Española y la crisis colonial del 98. Coordinado por José Antonio Ferrer Benimeli. Zaragoza: CEHME, 1999.

Gil Zúñiga, José Daniel. El culto a la Virgen de los Ángeles (1824-1935). Una aproximación a la mentalidad religiosa en Costa Rica. Alajuela: MHJS, 2004.

González Ortega, Alfonso. Vida cotidiana en la Costa Rica del siglo XIX. San José: EUCR, 1997.

Gueiros Vieira, David. O protestantismo a maçonaria e a questāo Religosa no Brasil. Brasilia: Editora Universidade de Brasilia, 1980.

Guerra, François-Xavier. México: del Antiguo Régimen a la Revolución. México D.F.: FCE, 1992.

Guzmán-Stein, Miguel. "Masones españoles en Costa Rica: el Krausismo y la Institución Libre de Enseñanza en la formación y desarrollo de la Democracia Liberal Costarricense". En Masonería Española y América. Coordinado por José Antonio Ferrer Benimeli. Zaragoza: CEHME, 1993.

Guzmán-Stein, Miguel. "Base de datos para la historia de la masonería en Costa Rica en el siglo XIX”. En La Masonería en Madrid y en España del siglo XVIII al XXI. Coordinado por José Antonio Ferrer Benimeli. Zaragoza: CEHME, 2004.

Guzmán-Stein, Miguel. "Dr. José María Castro Madriz: Masón y liberal, diputado, embajador, ministro, Presidente de la República, Presidente del Congreso, Presidente de la Corte Suprema de Justicia”. En La masonería española en la época de Sagasta (1825-1903). Coordinado por José Antonio Ferrer Benimeli. Zaragoza: CEHME y la Fundación Práxedes Mateo-Sagasta, 2006.

Guzmán-Stein, Miguel. "Masonería, Iglesia y Estado: Las relaciones entre el Poder Civil y el Poder Eclesiástico y las formas asociativas en Costa Rica (1865-1875)". REHMLAC 1, no. 1 (mayo-noviembre 2009): 100-134. Disponible en http://revistas.ucr.ac.cr/index.php/rehmlac/article/view/6859/6546

Guzmán-Stein, Miguel. "La lapidaria fúnebre-masónica en Costa Rica como fuente de investigación de una comunidad inédita". REHMLAC 1, no. 2 (diciembre 2009-abril 2010): 88-120. Disponible en http://revistas.ucr.ac.cr/index.php/rehmlac/article/view/6619/6308

Halévi, Ran. Les loges maçonniques aux origines de la sociabilité démocratique. Paris : Armand Colin, 1984.

Jacob, Margaret. Living the Enlightenment: Freemasonry and Politics in EighteenthCentury Europe. New York, U.S.A.: Oxford University Press, 1991. 
Koselleck, Reinhart. Critique and crisis. Enlightenment in the Pathogenesis of Modern Society. Traducido por Berg Publishers Ltd. Cambridge: MIT Press, 1988.

Lazega, Emmanuel. Réseaux socisux et structures relationnelles. Paris : PUF, 1998.

Levi, Geovanni. "Sobre Microhistoria". En Formas de hacer historia. Editado por Peter Burke. Traducido por José Luis Gil Aristu y Francisco Martín Arribas. Madrid: Alianza Universidad, 1993.

Madrigal Muñoz, Eduardo. “¿Deconstruyendo el Estado? Reflexiones en torno a una renovación teórico-metodológica". Número especial de Diálogos $9^{\circ}$ Congreso de Historia Centroamericano (2008): 3809-3826. Disponible en http://historia.fcs.ucr.ac.cr/articulos/2008/especial2008/articulos/12-Teoria/156.pdf

Madrigal Muñoz, Eduardo. "Prosopografía y redes sociales: por un nuevo paradigma historiográfico”. En Teoría y métodos de los estudios regionales y locales. Editado por Susan Chen Mok, Ana Paulina Malavassi Aguilar y Ronny Viales Hurtado. San José: SIEDIN-Universidad de Costa Rica, 2008.

Martínez Esquivel, Ricardo. "Composición socio-ocupacional de los masones del siglo XIX”. Diálogos Revista Electrónica de Historia 8, no. 2 (agosto 2007-febrero 2008): 124-147. Disponible en http://revistas.ucr.ac.cr/index.php/dialogos/article/view/18344/18536

Martínez Esquivel, Ricardo. "Un estudio comparado del establecimiento de logias masónicas en Costa Rica y Guatemala (1865-1903)". Número especial de Diálogos $9^{\circ}$ Congreso de Historia Centroamericano (2008): 2358-2382. Disponible en http://historia.fcs.ucr.ac.cr/articulos/2008/especial2008/articulos/07regional/100.pdf

Martínez Esquivel, Ricardo. "Masones y su participación política en Costa Rica (18651899)". Número especial de Diálogos $9^{\circ}$ Congreso de Historia Centroamericano (2008): 1815-1848. Disponible en http://historia.fcs.ucr.ac.cr/articulos/2008/especial2008/articulos/06-politica/76.pdf

Martínez Esquivel, Ricardo. "Documentos y discursos católicos antimasónicos en Costa Rica (1865-1899)". REHMLAC 1, no. 1 (mayo-noviembre 2009): 135-154. Disponible en http://revistas.ucr.ac.cr/index.php/rehmlac/article/view/6860/6547

Martínez Esquivel, Ricardo. "Conspiradores políticos y sectas misteriosas: Imaginarios sociales sobre la masonería en Costa Rica (1865-1899)". Revista Estudios 22 (2009): 13-32.

Martínez Esquivel, Ricardo. “Actividades masónicas en la Ciudad de Puntarenas (18701876)". Revista Inter Sedes VIII, n. 15 (2010): 93-108. Disponible en http://revistas.ucr.ac.cr/index.php/intersedes/article/view/870/931 
Martínez Esquivel, Ricardo. "Sociabilidad moderna, impugnación católica y redes masónicas en la Ciudad de Puntarenas (1870-1951)". En De Puerto a Región: El Pacífico Central y Sur de Costa Rica 1821-2007. Editado por Oriester Abarca Hernández, Jorge Bartels Villanueva y Juan José Marín Hernández. San José: SIEDIN-Universidad de Costa Rica, 2010.

Martínez Esquivel, Ricardo. "Inmigrantes libaneses en Costa Rica y sus participaciones en la masonería del país (primera mitad del siglo XX)". En 200 años de Iberoamérica (1810-2010). Coordinado por Eduardo Rey Tristán y Patricia Calvo González. Santiago de Compostela: Universidad de Santiago de Compostela, 2010. Disponible en https://halshs.archivesouvertes.fr/file/index/docid/529294/filename/AT4_MartinezEsquivel.pdf

Martínez Esquivel, Ricardo. "La masonería y el establecimiento de la Sociedad Teosófica en Costa Rica (1904-1910)". En La Masonería Española: Represión y Exilios. Coordinado por José Antonio Ferrer Benimeli. Zaragoza: CEHME, Gobierno de Aragón, Departamento de Educación, Cultura y Deporte, 2011.

Martínez Esquivel, Ricardo. «La Franc-maçonnerie à Puerto Limon: un espace de réception privilégié du cosmopolitisme dans une ville portuaire ». En La FrancMaçonnerie dans les ports. Editado por Cécile Révauger y Éric Saunier. Bordeaux : Presses Universitaires de Bordeaux, 2012.

Martínez Esquivel, Ricardo. "Modernity and Freemasonry in 19th Century Central America". Ponencia presentada en Liberalism and Religion: Secularisation and the Public Sphere in the Americas, University of London, 2012. Disponible en http://sasspace.sas.ac.uk/4146/1/LIA,_Modernity_and_Freemasonry,_Martinez,_18.04.12.pd $\underline{f}$

Martínez Esquivel, Ricardo. "Masones y Masonería en la Costa Rica de los Albores de la Modernidad (1865-1899)". Tesis de Maestría en Historia, Universidad de Costa Rica, 2012.

Martínez Esquivel, Ricardo. "Sociability, Religiosity and New Cosmovisions in Costa Rica at the turn of the Nineteenth to Twentieth Centuries". REHMLAC. Hors série $n^{\circ} 1$. Special Issue UCLA-Grand Lodge of California (2013): 155-191. Disponible en http://revistas.ucr.ac.cr/index.php/rehmlac/article/view/22482/22694

Martínez Esquivel, Ricardo. "Hacia la construcción de una historia social de la masonería en Centroamérica". Revista Estudios 27, no. 1 (2013): 127-151. Disponible en http://revistas.ucr.ac.cr/index.php/estudios/article/view/12703/11951

Martínez Esquivel, Ricardo. "Sociedad civil, esfera pública y masonería en Centroamérica (1865-1876)”. En Gibraltar, Cádiz, América y la masonería. Constitucionalismo y 
libertad de prensa, 1812-2012. Coordinado por José Miguel Delgado Idarreta y Antonio Morales Benítez. Gobierno de Gibraltar-Centro de Estudios Históricos de la Masonería Española, Universidad de Zaragoza, 2014.

Molina Jiménez, Iván. La Ciudad de los monos. Roberto Brenes Mesén, los católicos heredianos y el conflicto cultural de 1907 en Costa Rica. San José: EUCR y EUNA, 2008.

Molina Jiménez, Iván. La ciencia del momento. Astrología y espiritismo en Costa Rica durante los siglos XIX y XX. Heredia: EUNA, 2011.

Morales Benítez, Antonio. "Composición socio-profesional de los masones tarifeños del siglo XIX”. Aljaranda: revista de estudios tarifeños 13 (1994). Disponible en http://tarifaweb.com/aljaranda/num13/art7.htm

Obregón Loría, Rafael y George Bowden. La masonería en Costa Rica. San José: Trejos Hermanos, 1938.

Obregón Loría, Rafael. Presbitero Doctor Francisco Calvo (Ganganelli). Organizador de la Masonería en Costa Rica. San José: Imprenta Borrase, 1968.

Porset, Charles y Cécile Révauger eds. Le monde maçonnique des Lumières. EuropeAmérique et colonies. Dictionnaire prosopographique. Paris : Honoré Champion, 2013.

Pozuelo Andrés, Yván. "La historiografía masónica latinoamericanista actual. Presente y futuro". En 200 años de Iberoamérica (1810-2010). Coordinado por Eduardo Rey Tristán y Patricia Calvo González. Santiago de Compostela: Universidad de Santiago de Compostela, 2010.

Pozuelo Andrés, Yván. La masonería en Asturias (1931-1939). Oviedo: Universidad de Oviedo, 2012.

Renault, Agnès. "La influencia de la masonería francesa en el Departamento Oriental de Cuba en los años veinte del siglo XIX. Los aportes de la prosopografía". REHMLAC 1 no. 2 (diciembre 2009-abril 2010): 74-89. Disponible en http://revistas.ucr.ac.cr/index.php/rehmlac/article/view/6856/6543

Revel, Jacques. «Présentation a Levi, Giovanni ». En Le pouvoir au village: Historie d'un exorciste dans le Piémont du XVIIe siècle. Paris : Éditions Gallimard, 1985.

Rodríguez Dobles, Esteban. "Reconsiderando el Período Liberal: Mentalidad y Sociabilidad. Propuesta teórica para un estudio de las sociedades de creencias católicas y sus conflictividades ante la modernidad en Costa Rica, 1870-1935". Revista Estudios 22 (2009): 33-48.

Rodríguez Dobles, Esteban. “Conflictos en torno a las representaciones sociales del alma y los milagros. La confrontación entre la Iglesia Católica y la Sociedad Teosófica en 
Costa Rica (1904-1917)”. REHMLAC 2, no. 2 (diciembre 2010-abril 2011): 85-110.

Disponible en http://revistas.ucr.ac.cr/index.php/rehmlac/article/view/6598/6289

Rodríguez Dobles, Esteban. "Los debates periodísticos entre las sociedades de creencias: católicos, espiritistas y teósofos en la Costa Rica del cambio de siglo (1892-1935)". En Gibraltar, Cádiz, América y la masonería. Constitucionalismo y libertad de prensa, 1812-2012. Coordinado por José Miguel Delgado Idarreta y Antonio Morales Benítez. Gobierno de Gibraltar-Centro de Estudios Históricos de la Masonería Española, Universidad de Zaragoza, 2014.

Rodríguez Dobles, Esteban. "Redes Esotéricas en Centroamérica y Colombia 1904-1940. El caso de la Sociedad Teosófica". Ponencia presentada en el XIV Symposium Internacional de Historia de la Masonería Española. La masonería hispano-lusa y americana. De los absolutismos a las democracias (1815-2015), Universidad de Oviedo, 2015.

Rodríguez Dobles, Esteban. "Las formas de la eternidad y la pugna por el futuro. La Sociedad Teosófica en Costa Rica: imaginarios, creencias y conflictos (19041930)". Tesis de Maestría en Historia, Universidad de Costa Rica, 2016.

Sala, Céline. Franc-Maçonnerie et Sociabilité. En pays catalan au siècle des Lumières : un particularisme de frontière. Canet : Editions Trabucaire, 2005.

Sala, Céline. «La sociabilité maçonnique française à la croisée des frontières fraternelles et profanes: l'exemple de la ville de Perpignan au XVIIIe siècle ». REHMLAC 1, n. 2 (diciembre 2009-abril 2010): 2-16. Disponible en http://revistas.ucr.ac.cr/index.php/rehmlac/article/view/6614/6303

Sala, Céline. Les Francs-maçons en terres catalanes entre Lumières et Restauration. L'Art Royal de Perpignan à Barcelone (1740-1830). Paris : Éditions Honoré Champion, 2010.

Sánchez Solano, Esteban. "La identificación del desarticulador del mundo católico: el liberalismo, la masonería y el protestantismo en la prensa católica en Costa Rica (1880-1900)". REHMLAC 2, no. 2 (diciembre 2010-abril 2011): 34-52. Disponible en http://revistas.ucr.ac.cr/index.php/rehmlac/article/view/6595/6286

Sánchez Solano, Esteban. "La participación político-partidista de la Iglesia: El Partido Unión Católica y sus estrategias de movilización política en el marco del conflicto entre la Iglesia Católica y el Estado liberal en Costa Rica (1889-1898)". Tesis de Maestría en Historia, Universidad de Costa Rica, 2013.

Sánchez Solano, Esteban. "La Iglesia católica y el mundo de las ideas: el desafío del liberalismo como espacio social y político en Costa Rica (1850-1900)". En Gibraltar, Cádiz, América y la masonería. Constitucionalismo y libertad de prensa, 1812-2012. Coordinado por José Miguel Delgado Idarreta y Antonio Morales 
Benítez. Gobierno de Gibraltar-Centro de Estudios Históricos de la Masonería Española, Universidad de Zaragoza, 2014.

Sandí Morales, José Aurelio. "La Relación Estado e Iglesia católica en Costa Rica 18501920. En los procesos de Control del Espacio Geográfico y la Creación de un Modelo de costarricense". Tesis de Maestría en Historia, Universidad Nacional de Costa Rica, 2009.

Saunier, Éric. Révolution et sociabilité en Normandie au tournant des XVIIIe et XIXe siècles. 6000 francs-maçons de 1740 à 1830. Rouen : PURH, 1998.

Saunier, Éric. « Franc-maçonnerie et Révolution Française: vers une nouvelle orientation historiographique ». Cahiers d'histoire. Revue d'histoire critique 87 (2002). Disponible en http://chrhc.revues.org/1672

Saunier, Éric. "La prosopografía: una nueva vía para la Historia de la Masonería". REHMLAC 1, no. 2 (diciembre 2009-abril 2010): 37-42. Disponible en http://revistas.ucr.ac.cr/index.php/rehmlac/article/view/6616/6305

Stone, Lawrence. El pasado y el presente. Traducido por Lorenzo Aldrete. México D.F.: Fondo Económico de Cultura, 1986.

Torres, Abilio Jorge. "Composición socio-profesional en la masonería riojana". En Masonería, Política y Sociedad. Coordinado por José Antonio Ferrer Benimeli. Zaragoza: CEHME, 1989.

Torres, Abilio Jorge. “Composición socio-profesional de las Logias 'Zaragoza' en Cuba”. En La Masonería Española entre Europa y América. Coordinado por José Antonio Ferrer Benimeli. Zaragoza: CEHME, 1995. 